\title{
MATERNAL MORTALITY AT A TERTIARY CARE TEACHING HOSPITAL OF KERALA, SOUTH INDIA - A RETROSPECTIVE STUDY
}

Bindu VijayKumar' ${ }^{1}$ Uma Devi N², Suneetha Kalaam³ ${ }^{3}$ Ajitha ${ }^{4}$

\section{HOW TO CITE THIS ARTICLE:}

Bindu VijayKumar, Uma Devi N, Suneetha Kalaam, Ajitha. "Maternal mortality at a tertiary care teaching hospital of Kerala, south India - a retrospective study". Journal of Evolution of Medical and Dental Sciences 2013; Vol2, Issue 34, August 26; Page: 6428-6437.

BACKGROUND: Maternal death has been recognized as an area of maternal care that requires urgent attention. Making efforts to decrease maternal mortality is a matter of great concern to the obstetricians. MMR is a very sensitive index that reflects quality of reproductive care provided to the pregnant woman. OBJECTIVES: To assess the causes of maternal death and trends over a period of 5 years from July 2007 to July 2012 at a tertiary care teaching hospital of Kerala, South India. DATA AND METHODOLOGY: A retrospective hospital based study of maternal deaths which occurred over a period of 5 years from July 2007 to July 2012. The data regarding demographic profile and reproductive parameters were collected from patient's records. The results were analysed using percentage and proportion and Pearson's chi square analysis. The results have been compared with the scenario that existed 10 years ago. RESULTS: Over the study period there were 80,490 deliveries, (80217 live births) and 87 maternal deaths giving an MMR of 109/1, 00,000 LB. PPH was the most common direct cause while heart disease in pregnancy was the most common indirect leading cause. Most women died within 48 hours of admission. The age group 19-29 years was most affected. CONCLUSIONS: Most maternal deaths are preventable. Obstetric hemorrhage, toxemia of pregnancy and sepsis are the classic triad of the most important causes of maternal deaths. The provision of skilled care and timely management of complications can lower MMR in our setup. It's heartening to realize that our MMR was definitely touching MDG target, but Kerala overall has the distinction of having a MMR of 81 in 2007-2009 statistics as published by SRS, office of Registrar General, India.

KEYWORDS: Maternal mortality, postpartum hemorrhage, toxemia of pregnancy, developing country.

\section{ABBREVIATIONS:}

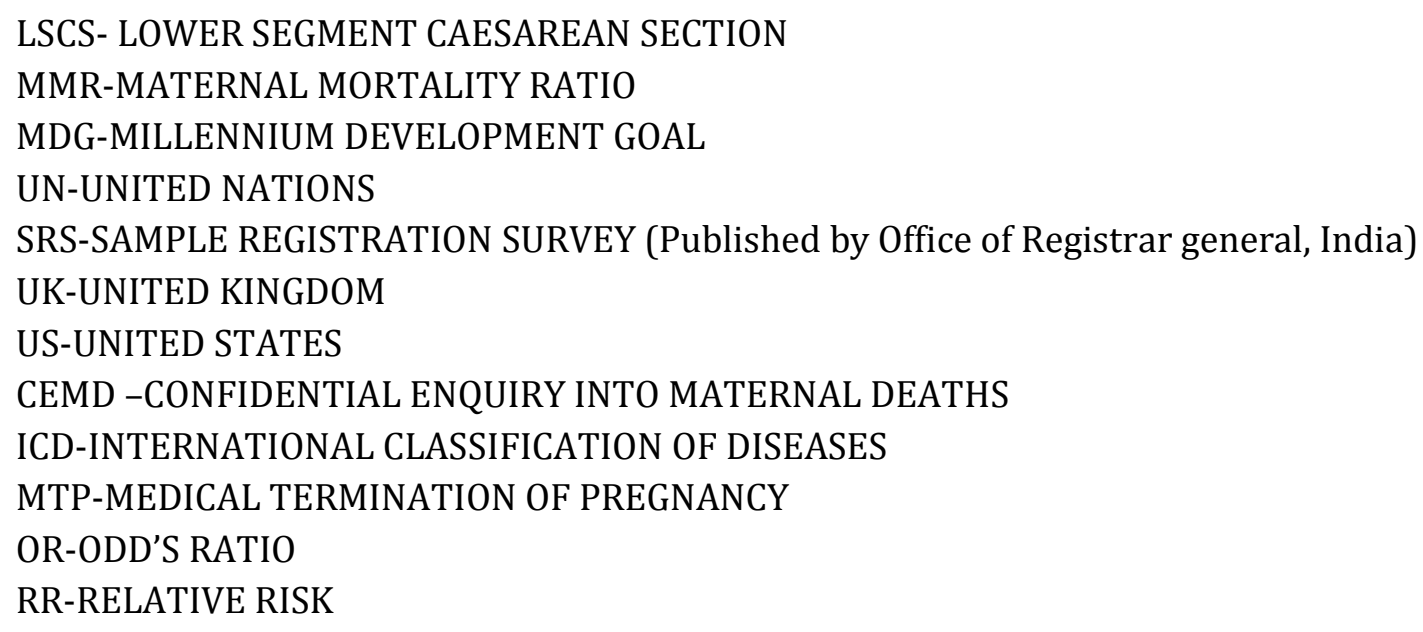




\title{
ORIGINAL ARTICLE
}

\author{
ARF-ACUTE RENAL FAILURE \\ ANC-ANTENATAL CARE \\ HDU-HIGH DEPENDENCY UNIT \\ AFE-AMNIOTIC FLUID EMBOLISM \\ VTE-VENOUS THROMBOEMBOLISM \\ HTN-HYPERTENSION \\ IMCH-INSTITUTE OF MATERNAL AND CHILD HEALTH, KOZHIKODE \\ NFHS-NATIONAL FAMILY HEALTH SURVEY
}

INTRODUCTION: Maternal mortality is an area of concern for the governments across the globe. The most striking feature about maternal health today is the extraordinary difference in maternal death rates between developed and developing countries. Maternal mortality is considered as the basic health indicator that reflects the adequacy of health care. The International conference on population development in 1994 had recommended reduction in maternal mortality by atleast 50\% of the 1990 levels by the year 2000 and to $75 \%$ by 2015. The MDG of the UN had set the target of achieving 200 maternal deaths per one lakh of live births by 2007 and 109 per one lakh of live births by $2015^{(1)}$.

The maternal mortality data in India from SRS is available for a period of 13 years from 1997-2009 which has shown a decline in MMR from 398 per 1 lakh live births in 1997-98 MMR survey to 212 (2007-2009, SRS). States realizing MDG target of 109 in 2007 to 2009 have gone up to 3 against 1 with Tamil Nadu and Maharashtra joining Kerala (4).

Even though Kerala enjoys relatively better maternal mortality figures than the rest of India, it is approximately 10 times more than developed countries (UK 12, US 8.4/1 lakh live births). One way to bring down Kerala's MMR further is to discover major underlying causes of maternal deaths in state. Hence confidential enquiry into maternal deaths which was successfully practiced in UK for more than half a century was most suitable for Kerala's setup.

Institutional data, though not an index of maternal care of the nation as a whole, highlights the magnitude of the problem (all referral hospitals have high rates of maternal mortality as they cater to high risk pregnancies).

DATA AND METHODOLOGY: Data included all maternal deaths which occurred in the department of Obstetrics and Gynecology, Medical College, Kozhikode which is a tertiary care referral centre of North Kerala (South India) over a period of 5 years from July 2007 to July 2012. A total of 87 maternal deaths occurred giving an MMR of 109/1, 00,000 live births.

The death records of women were reviewed. The definition of maternal death used in this paper is that recommended by the WHO in the International classification of diseases, injuries and causes of death (ICD 10). The number of live births and deliveries were obtained from the annual reports of our hospital.

MMR was computed and causes of maternal deaths were classified as direct and indirect causes. The distribution of maternal deaths by age, parity and place of residence, trimester of pregnancy at the time of death etc. were analysed. A separate analysis of hemorrhage related deaths were also done. No autopsies were performed due to social reasons.

Results were analysed using percentage and proportion and Pearson's chi square test. 


\section{ORIGINAL ARTICLE}

OBSERVATIONS: There were 80,217 live births and 87 maternal deaths with an MMR of 109/per 1 lakh live births.

As shown in table 1, nearly 70\% (59 cases) of women who died during pregnancy were young and in their active child bearing years (19-29 years). We had only 2 deaths in age group $<19$ years which may be due to the high level of female literacy, high age at marriage and liberalization of MTP laws. All patients were married.

$45 \%$ of the patients were primi gravidas and 55\% were multigravida. We had a total of 1043 grand multigravida who had come for delivery in our department during the study period. Doing a statistical analysis of maternal deaths in grand multigravida compared to deaths in the other groups (Primis + Multi gravidas) we got a OR of 9.95 (4.83-19.89) with a p value $<0.00001$ which was statistically significant.

As seen in table 1, 63.2\% of females had regular antenatal check ups and $75.9 \%$ belonged to rural areas. 12 patients among the total maternal deaths were tribals. 1500 tribals had delivered in our hospital during the $5 \mathrm{yr}$. period [OR $=8.46$; $95 \%$ CI for OR $(4.36-16.05$ ); $\mathrm{p}<0.00001)$ ]. The risk of a maternal death is more in the tribal population as seen from our results.

As seen from table 2, out of 87 deaths, 73 (84\%) of deaths occurred postpartum. There were 7 antepartum deaths, 6 cases following abortion and 1 intrapartum death.

In 74 patients (85\%), complications which initiated the chain of events that ultimately lead to maternal death occurred in the 3 rd trimester.

16 patients $(18.4 \%)$ were in moribund state at admission and 4 cases were brought dead.

As evident from table 3, the leading causes of maternal mortality were from hemorrhage, toxemia of pregnancy followed by sepsis. Direct causes contributed to $79.5 \%$ of deaths while indirect causes contributed to 20.5\%. The classic triad of infection, toxemia and hemorrhage accounted for more than $50 \%$ of all maternal deaths. Among the indirect causes, heart disease was the leading cause.

As shown in figure 1, on analyzing the time interval between delivery and death, $36.8 \%$ of patients died within 48 hours. Interval between delivery and death varied according to the cause of death.

As seen from figure 2, 61\% of patients who died due to PPH died within 24 hours of delivery. RR of death within 24 hours in case of PPH related deaths $=3$ (1.56-5.77), p value 0.0013 which was statistically significant. Similarly toxemia related deaths, 10/15 (66.7\%) patients died within one week $[\mathrm{RR}=2.03(1.22$ to $3.38, \mathrm{P}=0.016)]$.

$42.5 \%$ of maternal deaths were following LSCS and $42.3 \%$ were following vaginal delivery. The caesarean deaths were not purely related to surgery and anaesthesia as there were other associated comorbidities, for which a LSCS was done.

The most frequent pregnancy outcome associated with maternal death was live birth (65.5\%) followed by still births $19.5 \%$ and undelivered pregnancy (8.04\%).

On sub analysis of deaths among tribals hypertensive disorders accounted for maximum deaths as seen from figure 3 .

A subanalysis of deaths due to PPH was done. The details shown in table 4.

$28.5 \%$ were primiparous of which $75 \%$ were induced pregnancies.

$70 \%$ of patients were referred from periphery. More than $70 \%$ of the patients had a vaginal delivery and only 6 patients were following caesarean sections. $47 \%$ of the patients $(n=10)$ were 


\section{ORIGINAL ARTICLE}

brought to our institution in a moribund condition. Time lost during referral to a tertiary centre was analysed and it was seen that $70 \%$ of patients $(n=14)$ reached us after an average of 2-8 hours after delivery. 6 patients who died, delivered at our own centre which was an eye opener for us as we could not save their lives. There were only 2 home deliveries.

Atonicity was the major cause for PPH (19 cases ie. 90.4\% of all maternal deaths due to PPH) followed by placental problems in $10 \%$ of cases.

DISCUSSION: The event of a maternal death is a concern to the family, children, community and nation as a whole as it affects national productivity. MMR of Kerala is 81 per one lakh live births. This is 10 times more than the figures in developed countries. In the present study, our MMR was 109 per 1 lakh live births which are higher than the state average but all teaching referral hospitals have inflated rates of mortality as they cater to high risk pregnancies and they get moribund patients from periphery. Majority of women (70\%) who died during pregnancy were in 19-29 years age group and $11.5 \%$ were in the age group $>35$ years. Anandalakshmy et al (5) revealed that $80 \%$ of maternal deaths occurred in the age group 20-29 years. Kaur et al(6) revealed that $51.8 \%$ deaths occurred in $20-30$ years, $19.6 \%$ in teenage pregnancies and $23.3 \%$ in $>30$ years.

Primis accounted for $45 \%$ of maternal deaths. $11 \%$ of maternal deaths occurred in grand multiparas. Too many and too close pregnancies together adversely affect the mothers health and have its roots in the social status of the women. Maternal mortality was higher among women who had last child birth less than 2 years back.

In our study, $76 \%$ were from rural areas and $24 \%$ of the females were from urban areas. Our institution caters to a big tribal belt in North Kerala. Around $13.8 \%$ of maternal deaths occurred in the tribal population. Ignorance, illiteracy, customs and inaccessible dwelling places and poverty are factors against them. There is a prevalence of sickle cell disease among them.

In the present study, $84 \%$ of the deaths occurred in the postpartum period. WHO reported that $70 \%$ of all maternal deaths worldwide occurred during postpartum (3). Purandare et al (7) showed that $73.3 \%$ of maternal deaths were postpartum followed by $26.66 \%$ in antepartum and $3.3 \%$ in intrapartum period. The classical triad of the causes of maternal deaths is hemorrhage, toxemia and sepsis as reported by studies done worldwide. In our study also, hemorrhage accounted for $24 \%$ of deaths followed by toxemia (17\%) and sepsis (16\%). Amniotic fluid embolism accounted for $7 \%$ of all maternal deaths and venous thromboembolism for $9.2 \%$ of all maternal deaths. Among the indirect causes, heart disease was the most common cause followed by hepatitis. Valvular heart diseases (4 cases) topped the list followed by 3 cases of congenital disease complicated by pulmonary hypertension and 2 cases of peripartum cardiomyopathy and aortic dissection each. 2 patients who died following sickling crisis were tribals. Anandalakshmy et al reported $16.4 \%$ of deaths due to toxemia and $21.5 \%$ due to sepsis. Purandare et al (8) observed that among the direct causes, hemorrhage was responsible for $70.83 \%$ of deaths followed by sepsis $3.3 \%$ and among indirect causes, anemia in 55.3\%, hepatic disorders in 3.3\% and pulmonary embolism in $6.67 \%$. Recent SRS analysis showed that $38 \%$ of maternal deaths are caused by hemorrhage (4). In our study, anemia was a coexisting comorbid factor in 10 cases but anemia being the cause of maternal mortality was nil other than 2 sickle cell anemia cases. $60 \%$ of pregnant women were anemic according to NFHS 2006. Preexisting anemia worsens as gestation advances and reduces her 


\section{ORIGINAL ARTICLE}

immunity to infection or cope with hemorrhage and increases her likelihood of dying in child birth by a factor of $4(10)$.

Information regarding the time interval between end of pregnancy and death was important in that $25 \%$ of women died within 24 hours of delivery. In addition, interval varies with the cause of death. Late arrival at hospital was primarily responsible for the deaths attributed to hemorrhage. $70 \%$ of patients who died following PPH reached us after 2 hours of delivery (range being 2 - >8 hours). Here the importance of immediate resuscitation and the golden hour theory in PPH cannot be overlooked.

Concept of time of onset to death is important (9).

PPH - 2 hrs

APH - 12 hrs

Eclampsia - 2 days

Sepsis - 6 days

Majority of deaths due to PPH occurred within 24 hours. Health care has to be accessible if it is to be effective. Obstetric complications can be fatal within hours and access to adequate emergency obstetric care will decide whether a woman will live or die. Multi Organ Dysfunction took a toll in $80 \%$ of mothers with hypertensive disorders. This increased contribution from hypertensive disorders may be a pointer to the fact that even though we intervene early with good eclampsia control measures and early termination of pregnancy, any further reduction demands an increase in quality of care especially in high dependency unit care by intensivists and a multidisciplinary approach.

Anandalakshmy et al also supports that maternal mortality due to toxemia is mainly due to organ failure like ARF later. $73.6 \%$ of patients were high risk due to associated morbidities but the most striking fact is $26.4 \%$ of deaths were in women who did not have any risk factors and the turn of events were unexpected.

We had 4 maternal deaths in patients with sickle cell disease (2 were following sickle crisis, 1 death due to PPH and 1 severe pulmonary hypertension).

A comparative analysis was done with the statistics obtained for 5 years prior to 2000 and present study period which showed, as seen from figure 4, hypertensive deaths have come down over the years probably due to the use of magnesium sulphate and early termination of pregnancy but PPH and sepsis have actually shown a rise which is a cause for serious concern. But the deaths due to trauma (inversion and rupture uterus) and ectopic have come down to zero and jaundice related deaths have also shown a sharp decline.

CONCLUSION: Kerala is in the forefront of all states of India in health care delivery but we still have a long way to go to achieve single digit MMR figures. Major opportunity for Kerala in improving maternal health is that $99 \%$ of deliveries are institutional, attended by Medical Officers. A situational analysis of trends in obstetric care in Kerala has identified various avoidable errors and pitfalls which are changeable because of confidential enquiry into maternal deaths. This review stresses the need for increased emphasis on prevention and treatment of hemorrhage so that the foremost killer of women can be tackled by appropriate management. Elevation of sepsis as the third most common cause is frightening in spite of the availability of broad spectrum antibiotics. We 


\section{ORIGINAL ARTICLE}

have to improve our medical practices. Obstetric HDU's is a must in centres with more than 3000 deliveries in one year. Much needs to be done for maternal health care in rural areas as most of the deaths are being referred from peripheral centers. Hence a regular fact finding machinery is essential to analyze every maternal death so as to determine the causes and to adopt corrective measures in future.

Table 1: Socio demographic characteristics ( $n=87)$

\begin{tabular}{|c|c|c|c|}
\hline & Groups & Maternal deaths & Percentage \\
\hline \multirow{4}{*}{ Age (yrs) } & $<19$ & 2 & 2.3 \\
& $19-29$ & 59 & 67.8 \\
& $30-34$ & 16 & 18.4 \\
& $>35$ & 10 & 11.5 \\
\hline \multirow{3}{*}{ Parity } & Primi & 39 & 44.8 \\
& Multi & 38 & 43.7 \\
& Grand multi & 10 & 11.5 \\
\hline \multirow{2}{*}{ ANC } & Regular & 55 & 63.2 \\
& Otherwise & 32 & 36.7 \\
\hline \multirow{2}{*}{ Locality } & Rural & 66 & 75.9 \\
& Urban & 21 & 24.1 \\
\hline Tribals & - & 12 & 13.79 \\
\hline
\end{tabular}

Table 2: Delivery related characteristics $(n=87)$

\begin{tabular}{|l|c|c|c|}
\hline & Groups & Maternal deaths & Percentage \\
\hline \multirow{5}{*}{ Delivery status at death } & Antepartum & 7 & 8 \\
& Intrapartum & 1 & 1.1 \\
& Postpartum & 73 & 83.9 \\
& Abortion & 6 & 6.9 \\
\hline \multirow{3}{*}{ Stage of pregnancy at complications } & 1'trimester & 4 & 4.6 \\
& $2^{\text {nd }}$ trimester & 9 & 10.3 \\
& $3^{\text {rd }}$ trimester & 74 & 85 \\
\hline
\end{tabular}


Table 3: Causes of maternal death $(n=87)$

\begin{tabular}{|c|c|c|c|}
\hline & Maternal deaths & Percentage & \\
\hline \multicolumn{4}{|l|}{ Direct } \\
\hline Hemorrhage & 21 & 24.1 & \\
\hline Sepsis & & & \\
\hline Antepartum & 4 & $9.2\}$ & \\
\hline Puerperal & 10 & $6.9\}$ & 16.1 \\
\hline Septic abortion & 5 & 5.7 & \\
\hline Hypertensive disorders & 15 & 17.1 & \\
\hline Amniotic Fluid Embolism & 6 & 6.9 & \\
\hline Venous Thromboembolism & 8 & 9.2 & \\
\hline \multicolumn{4}{|l|}{ Indirect } \\
\hline Cardiovascular diseases & 9 & 10.2 & \\
\hline Hepatitis & 5 & 5.7 & \\
\hline Epilepsy & 2 & 2.3 & \\
\hline Sickle cell crisis & 2 & 2.3 & \\
\hline
\end{tabular}

Table 4: Subanalysis of deaths due to postpartum hemorrhage $(n=21)$

\begin{tabular}{|l|c|c|c|}
\hline \multirow{4}{*}{ Parity } & Groups & Maternal deaths & Percentage \\
\hline \multirow{5}{*}{ Referral time lost } & Primi & 6 & 28.5 \\
& Multi & 10 & 47.6 \\
& Grand multi & 5 & 23.8 \\
\hline \multirow{5}{*}{ Delivery death interval } & Delivered at IMCH & 6 & 28.6 \\
& $2-4 \mathrm{hrs}$ & 11 & 52.4 \\
& $4-8 \mathrm{hrs}$ & 3 & 14.3 \\
& $>8 \mathrm{hrs}$ & 1 & 4.8 \\
\hline \multirow{3}{*}{ Mode of delivery } & $24 \mathrm{hrs}$ & 10 & 47.6 \\
& $2-48 \mathrm{hrs}$ & 2 & 9.5 \\
& $>7$ days & 3 & 14.3 \\
& Spon. Vaginal delivery & 6 & 28.6 \\
\hline & Instrumental delivery & 2 & 61.9 \\
& LSCS & 6 & 9.5 \\
& & & 28.5 \\
\hline
\end{tabular}




\section{ORIGINAL ARTICLE}

Fig.1: Delivery death interval

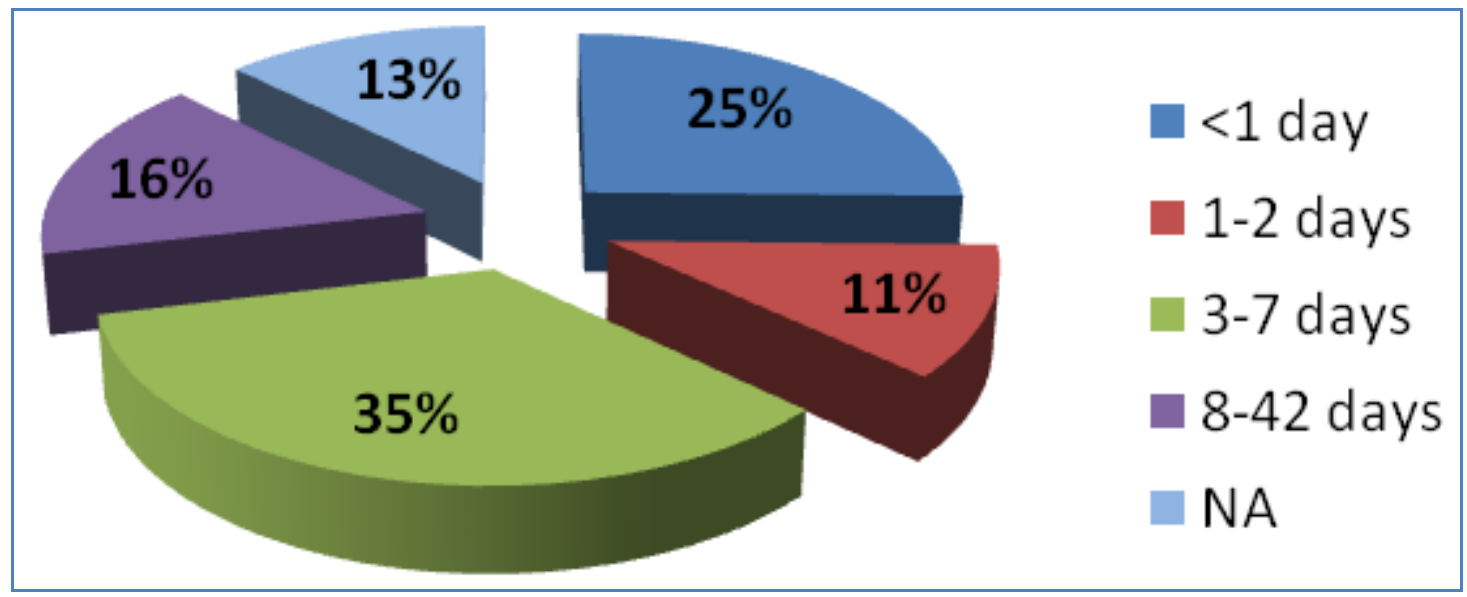

Fig.2: Distribution of causes and time interval

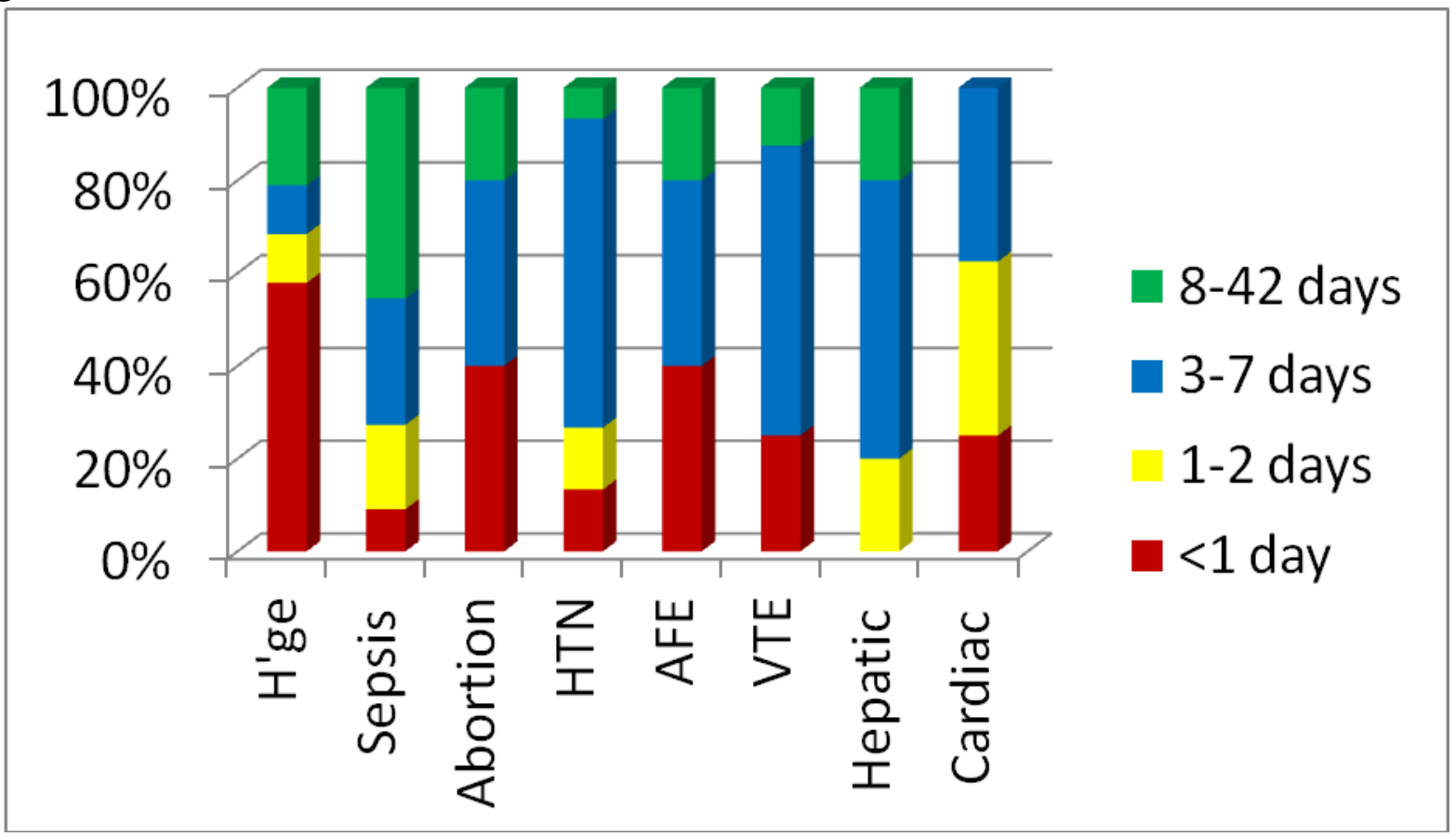

RR of death within 24 hrs in PPH $=3, \mathrm{p}=0.0013$

$\mathrm{RR}$ of death in 1 week in HTN $=2.03, \mathrm{p}=0.016$ 


\section{ORIGINAL ARTICLE}

\section{Fig.3: Causes of death among tribals}

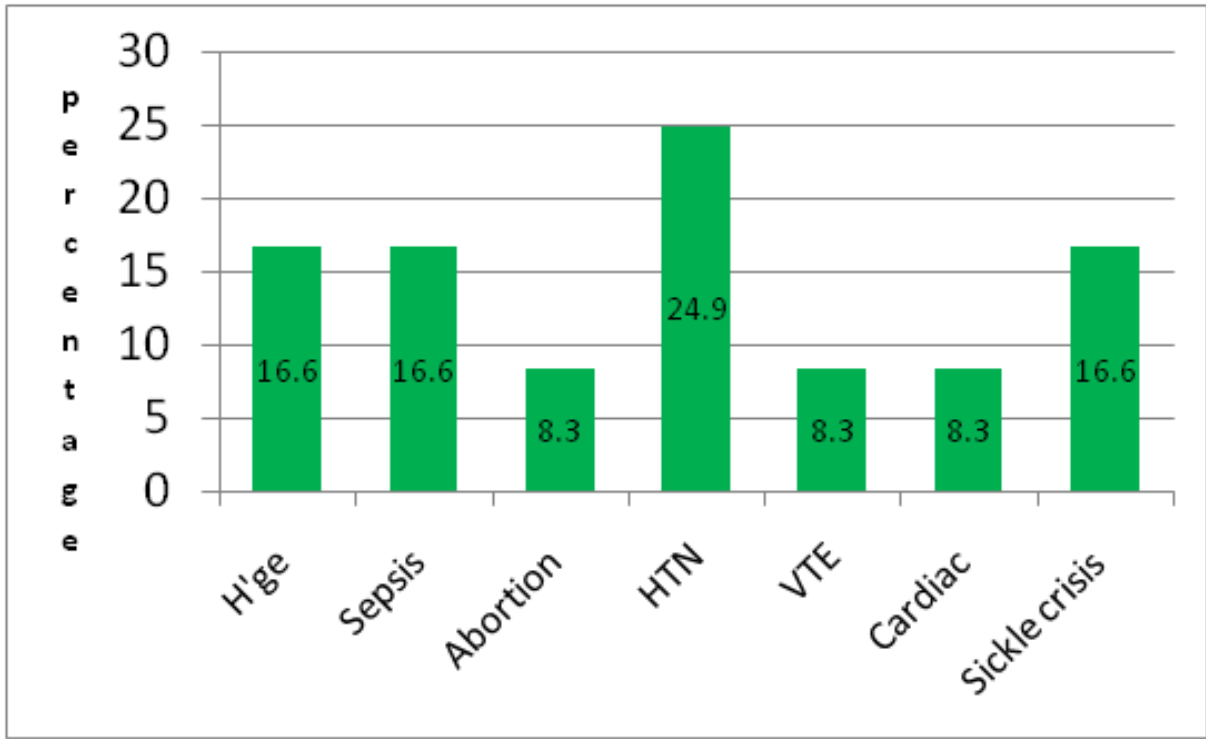

4 patients had sickle cell disease

Fig.4: Changes in trends.....

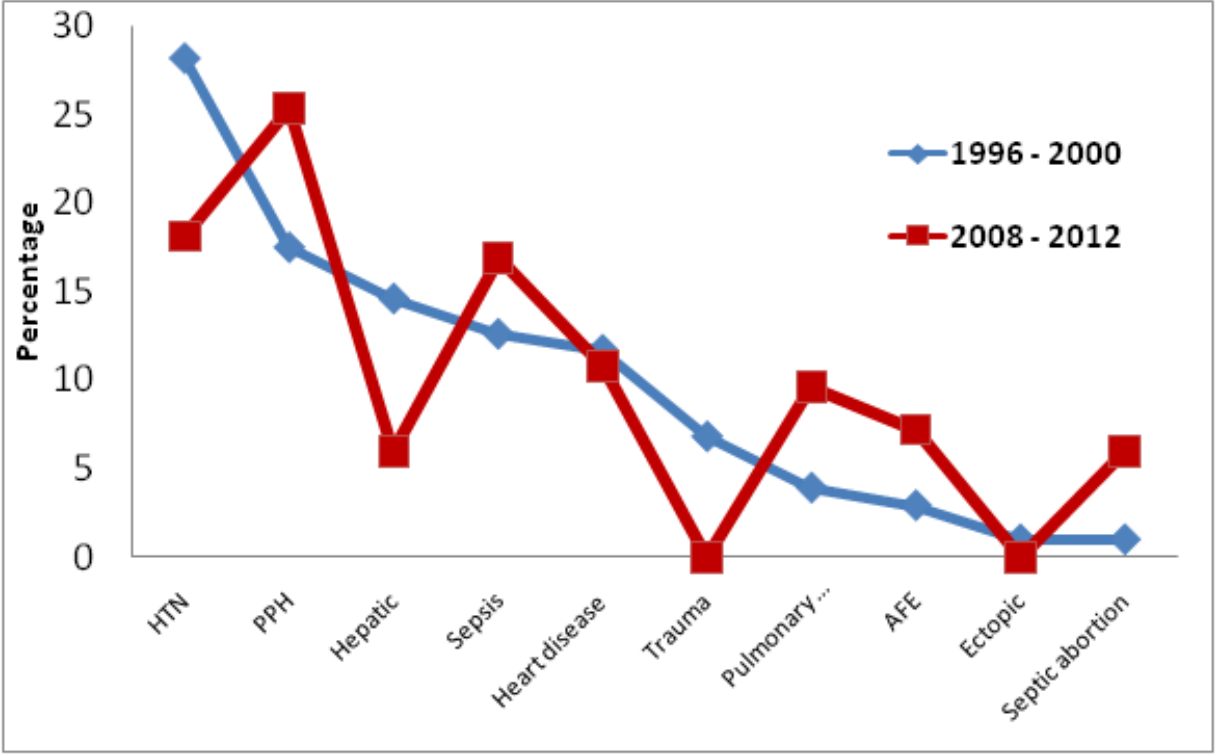

\section{REFERENCES:}

1. United Nations. UN millennium Development goals website. http://www.un.org/milleniumgoals/ accessed 1 Aug. 2009

2. World health organization 2010. "maternal mortality ratio (per, 100000 live births) “ WHO.web.4th Oct.2010

3. WHO, etal.2010. Trends in maternal mortality: 1990-2008.

4. Registrar general of India, maternal mortality in India. 1997-2003. Trends, causes and risk factors, Report 2006, Registrar General India. New Delhi, p1-29. 
5. Anandalakshmy, P.N, Bucksher K: maternal mortality in a referral hospital of Northern India: a sixteen year review. The journal of family welfare, Sep. 1997.43(3) p. 1-4.

6. Kaur Devinder, Kaur Amrupal. A retrospective study of maternal mortality in government medical college. Journal of obstetrics, Gynecology and family welfare. 1999; 5:18-22.

7. Purandare Nikhil, Singh Amarbaj, Upadhyyal Sangeeta, RM Saraogi. Maternal mortality at a referral centre: a five year study. Journal obstetric Gynaecol India. 2007; 57:248-250.

8. Anandalakshmy PN. Talwar PP, Bucksher K \& Hingo Jani V: demographic, socioeconomic and medical factors affecting maternal mortality - An Indian Experience, the journal of family welfare, 39(3): 1-4 (1993).

9. ACOG committee opinion - Number 283, May 2003. New US. Food \& drug administration labelling on cytotec (misoprostol) use \& pregnancy. Obstet Gynecol, 2003; 101:1049-50.

10. BediN. Kambo I, Dhillon BS, et al. Maternal deaths in India: Preventable tragedies. (an ICMR Task force study). J. Obstet Gynecol India, 2001; 51: 86-92.

11. World Health organization: WHO international classification of Diseases, Injuries \& causes of death (ICD - 9) world health organization, Geneva (1979).

12. Kumar, Rajesh, Sharad Kumar Singh, and Tanzin Dikid 2010. "Maternal mortality trends in India: Has the policy of promoting institutional delivery paid of" Indian Journal of Medical Research 132. 458-459. "India: Gains \& Gaps/" End Poverty 2015 millennium campaign. End poverty 2015, n.d.web. 23 Sep 2010.

13. V. Salvi.2009. "Maternal mortality in India: The true Killers." Journal of Postgraduate Medicine 55.1.1-2.

14. Park K .Preventive medicine in Obstetrics, Paediatrics \& Geriatrics. "Parks Text Book of Preventive \& Social Medicine. 20 $0^{\text {th }}$ edition: 2009. P.514-516.

\section{AUTHORS:}

1. Bindu VijayKumar

2. Uma Devi N.

3. Suneetha Kalaam

4. Ajitha

\section{PARTICULARS OF CONTRIBUTORS:}

1. Assistant Professor, Department of Obstetrics and Gynaecology, Government Medical College, Kozhikode, Kerala.

2. Professor \& HOD, Department of Obstetrics and Gynaecology, Government Medical College, Kozhikode, Kerala.

3. Assistant Professor, Department of Obstetrics and Gynaecology, Government Medical College, Kozhikode, Kerala.

\footnotetext{
4. Statistician, Department of Obstetrics and Gynaecology, Government Medical College, Kozhikode, Kerala.
}

\section{NAME ADRRESS EMAIL ID OF THE CORRESPONDING AUTHOR:}

Dr. Bindu VijayKumar, Sreekrishna, 33/5586, KSEB Substation Road, Chevayoor, P.O., Kozhikode, KERALA - 673017.

Email - bindu.vk@gmail.com
Date of Submission: 16/08/2013.
Date of Peer Review: 17/08/2013.
Date of Acceptance: 18/08/2013.
Date of Publishing: 22/08/2013 